\title{
Improving the financial stability of economic entities in the agricultural sector
}

\author{
Michail M. Chernyakov ${ }^{1, *}$, Maria M. Chernyakova ${ }^{2}$, Sergei S. Gromov ${ }^{3}$, and Saidmukhtori \\ S. Mukhtorzada ${ }^{4}$ \\ ${ }^{1}$ Novosibirsk State Technical University, 20, Karl Marx Ave., 630078 Novosibirsk, Russia \\ ${ }^{2}$ Russian presidential Academy of the national economy and public administration, 6, Nizhnegorskaya, \\ 630102 Novosibirsk, Russia \\ ${ }^{3}$ Private institution "RusAtom-international Network", 7/1, Stoletova str., Moscow, Russia \\ ${ }^{4}$ Tajik State University of Commerce, 734055, 1/2 Dekhoti Street, 119192 Dushanbe, Tajikistan
}

\begin{abstract}
The article analyses the financial stability of the Russian agrarian sector in Russia with consideration of regional characteristics of development in the context of digitalisation. A comprehensive system of absolute and comparative assessment of the agricultural industry stability was developed to test the hypothesis of its dependence on risks. An author's methodology for assessing agricultural risks of the digital economy was developed. A set of measures is proposed to improve the financial sustainability of agricultural production in the constituent entities of the Russian Federation.
\end{abstract}

\section{Introduction}

The introduction of "food sanctions" against Russia increased the interest of scientists in the analysis of such a scientific category as "financial stability" in the agricultural sector of the economy in the context of digitalisation [1]. The introduction of food sanctions is aimed basically at reorienting Russia's foreign trade markets in order to find suppliers free from the current politics. Reducing competition should help domestic agricultural producers to work effectively and take the leading positions in their food segment. The relevance of studying financial sustainability and emerging risks and threats to the regional food system in the process of transformation into a digital economy is due to the fact that without proper understanding and analysis of a significant number of economic problems, social and managerial relations in food circulation can arise both within the state and within the boundaries of a particular region. Svetlana Kurbatova, Valery Vlasov and Larisa Eisner made an attempt to show the risks and threats to food security in the region in the current economic situation [2], which they managed to do only partially.

The article by Elena Dadayan, Anna Storozheva and Ekaterina Letyagina [3] presents an up-to-date study focusing on the agricultural economic sphere of activity. They made it possible to identify economic risks affecting the financial stability of economic entities. Agricultural production growth, financial stability, etc., depend on how the actors overcome

${ }^{*}$ Corresponding author: mkacadem@mail.ru 
various economic risks. Economic risks can lead to the financial insolvency of agricultural enterprises.

The driving force behind modern economic development is the trend towards the introduction of digital technologies in various areas of life and activity, including the agroindustrial complex [4]. The formulation of the concept of agrarian risks in the digital economy (ARCE) is substantiated by the need to develop an appropriate methodological innovation-based diversification approach [4] to assess the possible risks of business entities of various levels and their impact on the readiness of organisations of the agro-industrial complex (AIC) for digital transformation.

In the study of Georgios Bartzas and Kostas Komnitsas [5], a holistic methodology was applied to integrate the life cycle analysis for environmental risk assessment with local farm and regional surveys using a multi-criteria hierarchical analytical process environment designed to identify the most sustainable agricultural management techniques at the regional level. The disadvantage of the applied hierarchical analysis is the assessment of only one environmental risk without taking into account digitalisation possibilities.

In an attempt to classify farms and markets in different groups based on their metrics, Jerome N. Barons et al. [6] used factor analysis for mixed data and hierarchical clustering. The characteristics and patterns of the proposed network can be used to create dynamic models. The disadvantage of the method used is the lack of consideration of possible risks, except for the health risk and the prospects for digitalisation of farms.

The intellectual system developed by V.A. Kuzmin et al. [7] for assessing the environmental safety of irrigated agricultural land and risks, built using the mathematical apparatus of fuzzy logic, made it possible to formulate recommendations for a set of necessary measures to prevent damage and minimise losses and to assess the effectiveness of their implementation in each specific case. The proposed model is limited to assessing the ecological safety of irrigated lands, i.e. environmental risk assessment.

A review of scientific publications showed that the main focus of the analysed studies was focused on a limited number of risks (environmental, health, social and politicalgovernance). A combination of methods of hierarchical and digital analysis, operations of mathematical logic and the set theory was used as the main methods for developing a mechanism for introducing digital technologies for business entities.

Hierarchical analysis used by E.V. Maslyukova in the study of the characteristics of the assessment and management of agricultural risks [8] made it possible to rank the reasons for the ineffective development of economic entities of the agro-industrial complex of the region. The main identified reasons included ineffective marketing, control and accounting of reserves and resources. However, the studies did not consider the possible risks of using digital equipment and technologies.

In the digital analysis technique proposed by I.B. Manzhosova [9] to assess the transformation processes in the agro-industrial complex during the transition to the digital economy, the characteristics of analytical blocks were developed. The main disadvantage of the proposed method is the lack of accounting for the agricultural risk impact in all analytical blocks. In order to increase the efficiency of this methodology, it should be modernised by adding mechanisms to its blocks to take into account the agrarian risks of the digital economy (Figure 1.25). In addition, the number and sequence of blocks should also be changed, and their content should be adjusted. The result of such a transformation is shown in [1]. By analogy with the method of I.B. Manzhosova, an author's methodology for assessing the agrarian risks of the digital economy (MOARCE) was proposed. 


\section{Research methodology}

In the process of research, general and particular scientific research methods were used [3], such as observation, analysis and synthesis, deduction and induction, which made it possible to identify economic risks affecting the financial stability of economic entities.

To implement the proposed algorithm for assessing the impact of ARDE on financial sustainability, it is necessary to collect initial information for analysis using questionnaires. The optimal collection option is filling out questionnaires for all eight blocks $\left(\mathrm{K} \mathrm{Te}_{\mathrm{e}}\right.$ technological, $\mathrm{K}_{\mathrm{Pe}}$ - social, $\mathrm{K}_{\mathrm{El}}$ - environmental, $\mathrm{K}_{\mathrm{Sa}}$ - sanitary, $\mathrm{K}_{\mathrm{En}}$ - economic, $\mathrm{K}_{\mathrm{Po}}$ - political, $\mathrm{K}_{\mathrm{In}}$ infrastructural, $\mathrm{K}_{\mathrm{Ma}}$ - psychological and managerial) by experts (managers and specialists of the economic entities, and by third-party specialists). The number of questionnaires is limited only by the number of possible experts who express their desire to participate in the survey.

Since there is information about typical representatives of the general totality (managers, specialists and outside experts), the quota method of spontaneous sampling based on the "snowball" principle was preferred. The assessment of the districts of the Novosibirsk region (30) included the heads and specialists of the administrations of the districts and the region, and the assessment of organisations (selectively from more than 390 thousand organisations) included the heads and specialists of enterprises and experts from the district administration, who agreed to compete the survey and also recommended new respondents matching the sample parameters.

Depending on the situation, the survey can be conducted both in the form of a questionnaire and as an interview, both face-to-face and in a remote format. Given the unfavourable epidemiological situation, the survey was carried out mainly remotely by telephone, and it was necessary to use all the advantages and reduce the disadvantages of this method.

\section{Research results and discussion}

According to the proposed algorithm, at the first stage, it is necessary to assess possible risks in the districts of the Novosibirsk region (NSO) using the MAARDE analysis. All 30 districts of the region were selected as the objects of the analysis. It was possible to conduct a detailed survey only for 12 districts; in the other districts, only an express survey was conducted. At the second stage, the number of indicators in each block is determined. Their value (Table 1) for three regions has an effective value (minimal risk), for three regions - a borderline value (acceptable) and 24 - an unsatisfactory value (unacceptable). This suggests that 24 districts of the region are technologically not ready for the process of digitalisation of agricultural organisations or that the preparation is at the initial conceptual stage.

Table 1. Results of scoring MAARDE-analysis with ranking according to the minimum value of the integral agricultural risk for 10 districts of the Novosibirsk region

\begin{tabular}{|c|c|c|c|c|c|c|c|c|c|}
\hline \multirow{2}{*}{ District } & \multicolumn{8}{|c|}{ MAARDE } & \multirow{3}{*}{$\mathrm{K}_{\mathrm{p}}$} \\
\hline & $\mathrm{K}_{\mathrm{Te}}$ & $\mathrm{K}_{\mathrm{Pe}}$ & $\mathrm{K}_{\mathrm{El}}$ & $\mathrm{K}_{\mathrm{Sa}}$ & $\mathrm{K}_{\mathrm{En}}$ & $\mathrm{K}_{\mathrm{Po}}$ & $\mathrm{K}_{\mathrm{In}}$ & $\mathrm{K}_{\mathrm{Ma}}$ & \\
\hline Risk potential & 0.14 & 0.14 & 0.14 & 0.14 & 0.12 & 0.12 & 0.10 & 0.10 & \\
\hline Maslyanino & 0.18 & 0.17 & 0.17 & 0.24 & 0.13 & 0.10 & 0.20 & 0.18 & 0.17 \\
\hline Kargat & 0.34 & 0.24 & 0.32 & 0.24 & 0.26 & 0.10 & 0.20 & 0.30 & 0.25 \\
\hline Ordynka & 0.37 & 0.24 & 0.36 & 0.24 & 0.22 & 0.10 & 0.20 & 0.38 & 0.27 \\
\hline Bagan & 0.42 & 0.36 & 0.47 & 0.52 & 0.32 & 0.80 & 0.20 & 0.41 & 0.44 \\
\hline Novosibirsk & 0.44 & 0.24 & 0.53 & 0.52 & 0.32 & 0.80 & 0.30 & 0.46 & 0.45 \\
\hline Suzun & 0.62 & 0.53 & 0.61 & 0.60 & 0.54 & 0.80 & 0.30 & 0.61 & 0.58 \\
\hline Iskitim & 0.75 & 0.62 & 0.70 & 0.60 & 0.74 & 1.00 & 0.30 & 0.75 & 0.69 \\
\hline Cherepanovo & 0.89 & 0.68 & 0.90 & 0.72 & 0.78 & 1.00 & 0.30 & 0.88 & 0.78 \\
\hline Krasnozerska & 0.91 & 0.76 & 0.79 & 0.60 & 0.86 & 1.00 & 0.38 & 0.91 & 0.78 \\
\hline Kuibyshev & 0.93 & 0.77 & 0.98 & 0.60 & 0.88 & 1.00 & 0.30 & 0.93 & 0.81 \\
\hline
\end{tabular}


At the third stage, the integral risk coefficient $\left(\mathrm{K}_{\mathrm{p}}\right)$ is calculated for each analytical block, taking into account their potential weight. The calculation results with a ranking according to the minimum value of the integral MAARDE are shown in Table 1 in the form of a summary table for all eight analytical blocks for the TOP-10 districts of the Novosibirsk region.

At the fourth stage, the results of the scoring MAARDE-analysis for each district (Table 1) allow developing a graphical model of the digital profile of the districts and the Novosibirsk region as a whole (Fig. 1).

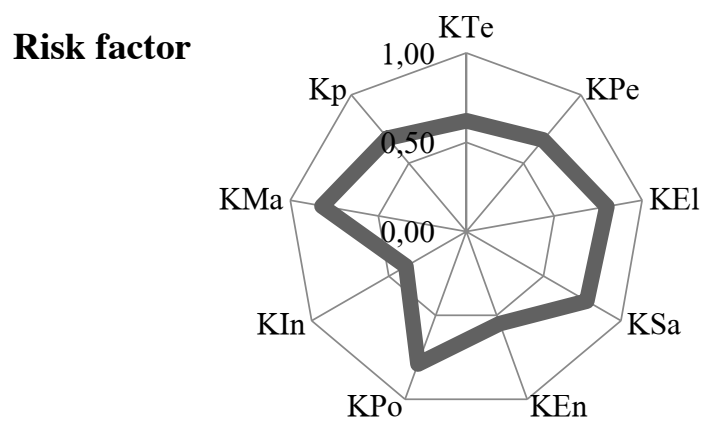

Fig. 1. MAARDE digital profile for the Novosibirsk region.

The digital district profiles (Table 1 and Fig. 1) allow one to identify the relative impact of the consequences of the potential impacts of the risks in each analytical unit. It was found that infrastructure risk is of the minor importance, which indicates the significant potential of economic entities in all districts of the Novosibirsk region to transform into a digital economy and improve financial sustainability.

At the fifth stage, the relative impact of the consequences of the potential impacts of the risks in each analytical block is identified. The political risk associated with an unstable international situation slows down the digitalisation process most strongly. The policy of sanctions and counter-sanctions allowed some branches of the agro-industrial complex to strengthen their positions, but this did not happen due to their accelerated digitalisation. Sanctions do not allow the use of advanced global digital technologies, and domestic developments are not enough for their intensive use. However, there is a positive experience of economic entities in the Maslyanino, Karagat and Ordynka districts. The influence of political risks in the processes of digitalisation there was reduced to a minimum and allowed these districts to take a leading position in the process of transformation into a digital economy.

Errors made in making managerial decisions (on the inclusion of the agricultural insurance system in the "single subsidy") led to an increase in the psychological and managerial risk and a massive refusal of agricultural organisations from agricultural insurance, which indirectly affected the growth of environmental and health risks, especially in the field of crop production and a little less in animal breeding. This can explain the high level of these three types of digital risks.

The high technological risk in most organisations in 24 districts is explained by a lack of financial resources for the acquisition of digital devices and technologies, and a shortage of skilled digitalisation specialists in 22 districts. Despite the fact that such specialists are trained in educational institutions in Novosibirsk, as a result of their moving to other regions and abroad, they do not stay in the agro-industrial complex in the required quantity due to its low attractiveness. In addition, the unemployment rate, which increased fivefold in 2020, also contributed to the growth of social risk. 


\section{Conclusions}

The study showed that the agro-industrial complex of the Novosibirsk region as an object of transformation into the digital economy has an acceptable level of digitalisation risk, but, from the point of view of readiness for its implementation, there is a clear need for a series of transformations in the industry. Agricultural sector digitalisation should be carried out continuously and be of a pilot nature. To solve this problem, it is advisable to develop a set of pilot projects and a list of measures in various areas of agricultural industry development in the digital economy.

The results of the study, while stating the significant role of the digital economy in different countries, made it possible to assess the potential for digital transformation in the region, which is characterised by fairly active use of digital technologies in the economy as a whole, but not sufficiently in the agricultural sector. The Novosibirsk region took second place among the top 10 entities in terms of readiness to implement digital technologies in the agro-industrial complex. However, it has insufficient innovative activity for taking full advantage of the existing opportunities. The study of the possibilities of introducing digital technologies in the agricultural sector, which will determine the prospects for its further functioning, was carried out using such an analytical tool as a survey of managers, specialists and experts working for a long time in the agricultural sector, which contributed to forming specific conclusions and identification of a set of significant patterns.

Critical political and psychological, and managerial risks were identified. They are characterised by the low efficiency of state support to the agro-industrial complex, an acute shortage of financial and highly qualified labour resources, which has a negative indirect impact on other types of risks and the integral risk in general. Practical application of recommendations that reduce agricultural risks, differentiated by the nature of their impact on the introduction of digital technologies in the agricultural sector, will allow for a more balanced policy in the transition to a digital economy.

\section{Acknowledgements}

The work was done with the help of Novosibirsk State University (project C21-11).

\section{References}

1. M. K. Chernyakov, M. M. Chernyakova, I. A. Chernyakova, IOP Conference Series: Earth and Environmental Science, 723 (2021)

2. S. M. Kurbatova, V. V. Vlasov and L. Yu. Eisner, E3S Web of Conferences, 161, 01089 (2020)

3. E. Dadayan, A. Storozheva, E. Letyagina, E3S Web of Conferences, 161, 01065 (2020)

4. M. K. Chernyakov, M. M. Chernyakova, I. A. Chernyakova, IOP Conference Series: Earth and Environmental Science, 624 (2021)

5. G. Bartzasa and K. Komnitsas, Information Processing in Agriculture, 7(2) (2020)

6. J. N. Baron, M. N. Aznar, M. Monterubbianesi, B. Martínez-López. PLoS ONE, 15(6), e0234489 (2020)

7. V. A. Kuzmin, K. E. Tokarev, A. Yu. Rudenko, T. V. Pleshchenko, II IOP Conf. Series: Earth and Environmental Science, 577, 012008 (2020)

8. E. V. Maslyukova, Russian Entrepreneurship, 16 (2017)

9. I. B. Manzhosova, Moscow Economics Journal, 3 (2018) 